\title{
Investigation of the relationship between the diaphragm muscle relaxation therapy, voice emission and postural stability in amateur and professional singers of Academy of Music - preliminary study
}

\author{
Ciuryk Julia ${ }^{1}$, Michalik Dominika ${ }^{2}$, Hordyjewicz Katarzyna ${ }^{3}$, Małecki Pawel ${ }^{4}$, \\ Frankowski Grzegorz $^{5}$, Klaczyński Maciej ${ }^{6}$, Kulesa Mrowiecka Malgorzata ${ }^{7}$ \\ 1,2,3Jagiellonian University Medical College, Faculty of Health Science, Institute of Physiotherapy, \\ Student Scientific Group of Physiotherapy and Neurorehabilitation, 12 Michalowskiego Str., \\ 31-143 Krakow, Poland \\ ${ }^{4,6} \mathrm{AGH}$ University of Science and Technology, Faculty of Mechanical Engineering and Robotics, \\ Department of Mechanics and Vibroacoustics, al. A. Mickiewicza 30, 30-059 Krakow, Poland \\ 5,7Jagiellonian University Medical College, Faculty of Health Science, Institute of Physiotherapy, \\ Department of Physiotherapy, 12 Michalowskiego Str., 31-143 Krakow, Poland \\ ${ }^{7}$ Corresponding author \\ E-mail: ${ }^{1}$ julia.ciuryk@student.uj.edu.pl, ${ }^{2}$ dominika.michalik@student.uj.edu.pl, \\ ${ }^{3}$ katarzyna.hordyjewicz@student.uj.edu.pl, ${ }^{4}$ pawel.malecki@agh.edu.pl, ${ }^{5}$ grzegorz.frankowski@uj.edu.pl, \\ ${ }^{6}$ maciej.klaczynski@agh.edu.pl, ${ }^{7}$ m.kulesa-mrowiecka@uj.edu.pl
}

Received 14 September 2020; accepted 28 September 2020

DOI https://doi.org/10.21595/jme.2020.21707

Check for updates

Copyright (C) 2021 Ciuryk Julia, et al. This is an open access article distributed under the Creative Commons Attribution License, which permits unrestricted use, distribution, and reproduction in any medium, provided the original work is properly cited.

\begin{abstract}
The present study aims at presenting the impact of manual diaphragm relaxation therapy on the voice emission tested in an anechoic chamber and changes in the body posture during singing using the Zebris posturographic and pedobarographic platform. A pilot study on three cases has been conducted (patient 1 - male aged 21, student of the 2nd year of Academy of Music in Krakow, patient 2 - male aged 34, with more than 25 years of choral singing and advanced musical experience, patient 3 - female 24, with around 10 years of choral singing experience and primary musical school graduation). An original survey questionnaire was used, enabling determination the problematics associated with the profession of singer. A posturographic platform (Zebris) was used that revealed deviations during the scenic movement (by performing an appropriately developed repertoire). Subsequently, a voice emission examination was carried out in an anechoic chamber of the Department of Mechanics and Vibroacoustics, AGH University of Science and Technology. Directly after the examination, the examined individual was subject to a manual therapy lasting several minutes. The applied fascial techniques for diaphragm consisted in the implementation of a prolonged stretching of the myofascial complex with the use of low load. After the therapy, testing with the use of the aforementioned methods was repeated. The present study refers to the impact of the diaphragm function on voice emission parameters. In the pilot study for patient 1 and 2, 15 voice emission parameters improved. The analysis of the above results showed the variability before and after the diaphragm relaxation therapy in parameters such as Fo, Jitt and Shim. In the examined case of patient 1 and 2, the value of the parameter Jitt decreased by almost half, while Shim decreased by about $40 \%$ after the therapy. However, such changes were not observed for patient 3 . It may be influenced by many factors, such as stress or worse disposition on the day of the examination. The presented preliminary study expands the knowledge on the function of the diaphragm and the awareness of the function of ventilatory muscles during singing, which may result in enhanced efficiency of working with voice. In the future it is planned the study on bigger group students of Academy of Music in Krakow with the control group.
\end{abstract}

Keywords: diaphragm muscle, relaxation therapy, voice emission, singers, postural stability. 


\section{Introduction}

Vocal prevention and hygiene should be the priority for teachers, choir conductors, singers etc. This is particularly important field that should be trained already at the lowest levels of education of work with voice. Studies on the impact of diaphragm on the body posture are also becoming increasingly common [1]. The biomechanical understanding of maintaining balance is considered as the capability of an individual to minimize the movement from the center of relative to the support plane. It has been proven that the diaphragm is activated in the phase of preparation to tasks that result in imbalance. It fulfills two functions at the same time: ventilation and stabilization. In the situation of increased ventilatory load diaphragm reduces the stabilization function. Vostatek et. al. demonstrated a significant relationship between the loss of stability of the lower part of the vertebral column relative to the increased demand for ventilation [2].

Voice emission is a process of producing and releasing voice externally. The process occurs due to coordinated actions: breathing, phonation, articulation and thus formed resonance [3]. The specificity of tissue connectivity due to fascial connections, by means of relaxation of the diaphragm, enables reducing the tension in the laryngeal area, which may contribute to correct impostation [4]. Aligning the pelvis in an intermediate position and correct loading of the knee and foot joints enable correct action of the diaphragm. Movement of the center of gravity posteriorly may result in increased lumbar lordosis and expansion of the abdominal muscles, whereas leaning backwards significantly disturb the movement of the chest [5]. The correct tension in the orofacial area is directly affected by the dynamic action and properly taut diaphragm. From the anatomical standpoint, it is a significant organ separating the abdominal cavity from the thoracic cavity [6]. It plays a significant role in maintaining the posture, understood as the torso stability and control during repeated motor function. The mentioned processes are highly dependent on the diaphragm function during ventilation, thus it can be concluded that it fulfills postural and ventilation function at the same time [7].

Singers are frequently unaware of the presence of acquired, unfavorable movements and improper tension of the muscles and tissues surrounding the larynx and diaphragm, which are associated with functional disorders of voice [8]. Individuals diagnosed with voice disorders show clavicular ventilation, which is inefficient from clinical standpoint and may be changed into being more efficient after physiotherapeutic intervention [9].

Professional classical singers are often in favor of active control of the abdominal cavity and of the thorax during performance. It is believed that this disables the diaphragm shortening, raises the thorax and thus contributes to a greater efficiency of subglottic pressure formation during phonation. However, these patterns have been quantitatively analyzed in only few studies, and the interpersonal variability has impeded identification of the stereotypical patterns of respiratory kinematics. It should be noted that the previous research demonstrated that in contrast to amateur singers, classical singers are characterized by a greater percentage contribution of the abdominal cavity in the lung volume during singing and the ability to desynchronize the movements of the thoracoabdominal movement. The movement of the abdominal press observed in classical singers affects the increase of pressure in the abdominal cavity. This phenomenon results in increased length and capability of thoracic expiratory muscles to produce pressure, which may enhance voice quality [10].

The described physiological process of subglottic pressure formation is highly significant for singers, but at the same time the disturbed balance of thoracic and abdominal press movement may lead to esophageal reflux. Gastroesophageal reflux is a condition caused by rapid change of the subglottic pressure in the abdominal cavity during diaphragm action, which results in increased intraabdominal pressure. The mentioned processes disable normal function of the diaphragm sphincter, as a result of which the mechanisms repeated over many years increase the likelihood of reflux incidence in singers [11].

It should be noted that the so-called Performance-Related Musculoskeletal Disorders (PRMD) can be observed among singers. Research shows that $79 \%$ of singers experience PRMD before 
commencing music education at the university level. The incidence rate of PRMD is strongly correlated with the daily, long-hours of repeating the same movements, disturbed postural patterns, lack of proper work hygiene or the absence of regeneration strategies, as well as sedentary lifestyle [12].

The role of the fascia in human body is significant due to its common distribution and direct impact on healthy structures. The connective tissue forming fascia is a type of system, which by penetrating the muscles, nerves, blood vessels etc. forms a three-dimensional metabolic matrix. The lack of possibility displacement of fascia layers may have a significant impact on the quality of ergonomic physical activity. The structure of fascia is characterized by a considerable number of proprioceptors, which are located mainly in the areas between the fascia and contractile elements, such as muscles. What is more, fibroblasts forming the basis for the fascia, thanks to their capacity to change the vector, recreate the current mechanical vector, thus the transfer of the produced tension is more ergonomic and smoother. It has been proven that pathologic disturbance associated with the fascia system maintaining for a prolonged period of time may result in chronic muscle fatigue and pain [13].

\section{Research material and methodology}

A pilot study on three cases has been conducted (patient 1 - male aged 21, student of the 2nd year of Academy of Music in Krakow, patient 2 - male aged 34, with more than 25 years of choral singing and advanced musical experience, patient 3 - female 24, with around 10 years of choral singing experience and primary musical school graduation).

An original survey questionnaire was used, enabling determination the problematics associated with the profession of singer (i.a. pain of musculoskeletal origin, gastroesophageal reflux, resistance to stressful situations). A posturographic platform (Zebris) was used that revealed deviations during the scenic movement (by performing an appropriately developed repertoire). Subsequently, a voice emission examination was carried out in an anechoic chamber of the Department of Mechanics and Vibroacoustics, AGH University of Science and Technology. Directly after the examination, the examined individual was subject to a manual therapy lasting several minutes. The applied fascial techniques consisted in the implementation of a prolonged stretching of the myofascial complex of the diaphragm with the use of low load. In this manner, the domes and crura of the diaphragm were studied.

The person conducting the therapy sensed the most restricted direction of fascia displacement and applied pressure mobilization of soft tissues, directly on the skin and deeper in the fascia, until resistance was felt. Subsequently, the movement was stopped for several minutes, without displacement, until the fascia was relaxed (soft final resistance). The technique was coordinated with diaphragmatic breathing (Table 1). One series of each technique, 8 repetitions, time depends on individual breathing tempo. Break between each technique -2 minutes. In physiotherapy techniques, therapist places palms under the osteochondral connections, thus stimulating ventilatory function [14].

\subsection{Description of the techniques used}

After the therapy, testing with the use of the aforementioned methods was repeated. Information sheet was given to patients and a verbal explanation of the nature of the study by the investigator. The patients agreed to participate in the study, an informed consent was signed. The study was conducted in accordance with the amended Declaration of Helsinki. Zebris FDM-S platform was used to assess stabilometric parameters of balance. The device was force-measuring platform with built-in capacitive force sensors enabling the measurement and analyses of force distribution under the feet (dimensions: $69 \times 40 \times 2.1 \mathrm{~cm}$, Sensor surface: $54 \times 33 \mathrm{~cm}$, number of sensors: 2,560, sampling rate: $120 \mathrm{~Hz}$ ). In assessing static stability, patients stood barefoot in a natural and relaxed position, with arms by the sides. During the assessment of stability, subject 
was asked to stay for 1 minute and test was repeated 3 times with a 5 sek. break. Volunteer completed the static balance task under two conditions: 1. test before myofascial techics, and 2 . after treatment with 30 minutes break between each measurement.

Table 1. The techniques for relaxation of diaphragm

\begin{tabular}{|c|c|c|c|}
\hline No. & Starting position & Technique & Aim \\
\hline 1. & $\begin{array}{l}\text { Supine hook lying } \\
\text { position }\end{array}$ & $\begin{array}{l}\text { - Physiotherapist was turned towards subject's head } \\
\text { - Physiotherapist's hands located laterally on subject's } \\
\text { chest with thumbs under costal arch } \\
\text { - Study participant breathes calmly with diaphragm } \\
\text { pattern } \\
\text { - Next, while subject exhales, physiotherapist breaks } \\
\text { soft tissue barrier with thumbs through deep } \\
\text { myofascial relaxation } \\
\text { - Physiotherapist with subject's every exhale, move } \\
\text { thumbs inferiorly (40-45 seconds, } 8 \text { repetitions) } \\
\text { - At the end, physiotherapist slowly releases the grip }\end{array}$ & $\begin{array}{l}\text { Relaxation of central } \\
\text { tendon of diaphragm } \\
\text { (diaphragmatic } \\
\text { leaflets) }\end{array}$ \\
\hline 2. & $\begin{array}{l}\text { Supine hook lying } \\
\text { position }\end{array}$ & $\begin{array}{l}\text { - Physiotherapist is turned towards subject } \\
\text { - Physiotherapist's flat hands located laterally on } \\
\text { subject's chest (level of V-VIII rib) } \\
\text { - Study participant breathes calmly from a diaphragm } \\
\text { - Next, while subject exhales, physiotherapist press the } \\
\text { chest resulting in deepening the exhale } \\
\text { - Study participant performs inhale, while } \\
\text { physiotherapist leaves hands in the same position, } \\
\text { creating a resistance for subject's inhale } \\
\text { - After } 2 \text { seconds, physiotherapist releases the } \\
\text { resistance, allowing patient to fully inhale }\end{array}$ & $\begin{array}{l}\text { Relaxation of central } \\
\text { tendon of diaphragm } \\
\text { (diaphragmatic } \\
\text { leaflets) }\end{array}$ \\
\hline 3. & $\begin{array}{l}\text { Sitting position on } \\
\text { chair without back } \\
\text { support, lower limbs } \\
90 \text { degrees flexed, } \\
\text { hands on knees }\end{array}$ & $\begin{array}{l}\text { - Physiotherapist sits behind study participant } \\
\text { - Physioterapist's hands located on posterior wall of } \\
\text { subject's chest with thumbs under costal arch in the } \\
\text { area of erector spinae muscles } \\
\text { - Study participant breathes calmly from a diaphragm } \\
\text { - Next, while subject exhales, physiotherapist breaks } \\
\text { soft tissue barrier with thumbs located under costal } \\
\text { arch through deep myofascial relaxation } \\
\text { - Physiotherapist with subject's every exhale, move } \\
\text { thumbs inferiorly (40-45 seconds, } 8 \text { repetitions) } \\
\text { - At the end, physiotherapist slowly releases the grip }\end{array}$ & $\begin{array}{c}\text { Relaxation of } \\
\text { posterior branch of } \\
\text { diaphragm }\end{array}$ \\
\hline
\end{tabular}

The following stabilometric quantitative parameters were considered: path (total length of center of gravity displacement), ellipse (area in which the center of gravity oscillates), left and right side loading, back and fore side loading.

\subsection{Singin procedure}

The singing procedure is consisted of basic vocal exercises that was designed in order to observe the basic features of voice emission. In particular, the experiment was to analyze the relative quantity of tonal stability and musical dynamics within one long note. The procedure was performed before and after diaphragm muscle relaxation therapy to determine if there are any changes in the quality of the produced sound and what is their magnitude. The scheme of the singing exercises is shown in the Fig. 1.

The consecutive stages of the procedure are illustrated by the logical blocks. The chosen vocal exercises are very basic and simple so each singer could focus on the sound emission only, and not pay any attention on the musical aspects or the exercises content. The first stage of recording 
voice was a rough identifying of the vocal range so the following exercises were performed in a convenient register for each singer individually. The second exercise (Fig. 2) was to sing major scale in a tempo of about 60 BPM (Beats Per Minute), with solmization in $m f$ dynamics (it. mezzoforte: medium loud), starting a third (three semitones) above the previously determined lower range of the vocal range. The subjects were instructed to do this exercise in one breath and sing the last, highest note as long as possible.

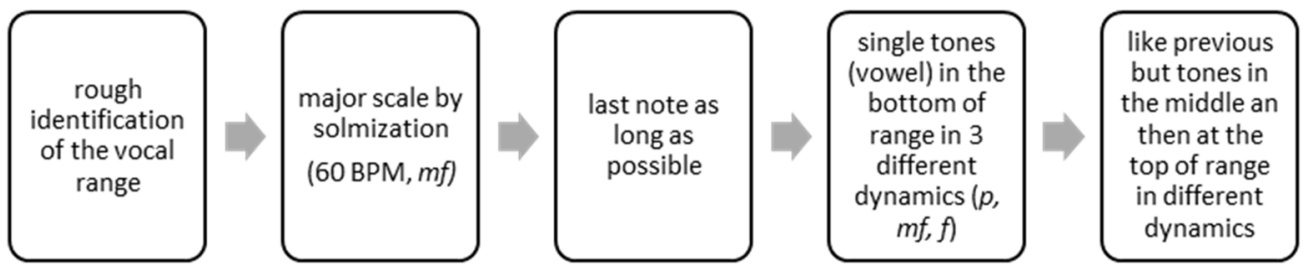

Fig. 1. Scheme of singing procedure to establish tonal and dynamic quality of the voice before and after the therapy

The next exercises were to sing simple single tones, in a most comfortable vowel for a particular singer, in one breath. Each pitch was singing in three different dynamics: $p, m f, f$ (it. piano, forte: softly, loud). The person conducting the experiment before every round gave the base notes pitches in relation to the previously measured vocal range, i.e. in its low range (third above the bottom of the range), in the middle of the range and in the high range (third below the designated top of the scale). In every case, the subject task was to keep the sound stable and steady as long as possible, in the given pitch and dynamics.

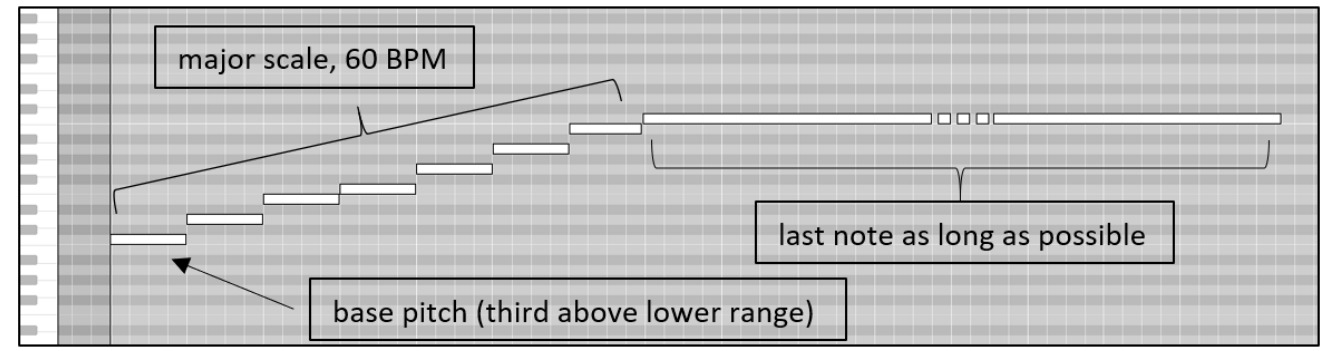

Fig. 2. Major scale singing in a $60 \mathrm{BPM}$, with solmization and mf dynamics

\subsection{Voice emission recording and parametrization}

The time-dependent acoustic speech signal was recorded in an anechoic chamber [16], at the Department of Mechanics and Vibroacoustic, AGH University of Science and Technology, Krakow, Poland. The diagram of the measurement setup is shown in Fig. 3. The applied professional registration system provided a transfer band from $20 \mathrm{~Hz}$ to $20 \mathrm{kHz}$ at the dynamics amounted to not less than $80 \mathrm{~dB}$.

The registered research material (described in 2.2) has been used for creation of a database, containing acoustic signal samples, recorded in the "wave" format. The impact of muscle relaxation therapy on voice emission has been based on parameters resulting from changes of the primary tone function $-F_{0}$. The respective parameters have been divided into following groups with respect to [17]:

- base frequency (Fo, Fhi, Flo, T0, PFR, STD),

- fluctuation of the base frequency (Jitta, Jitt, PPQ, RAP, sPPQ, vF0),

- fluctuation of signal amplitude (ShdB, Shimm, APQ, sAPQ, vAm),

- variation of the signal's time sections (NSH, NUV, NVB, DSH, DUV, DVB)

- noise present in the signal (VTI, SPI, NHR) 
- tremble (Fatr, Fftr, ATRI, FTRI).

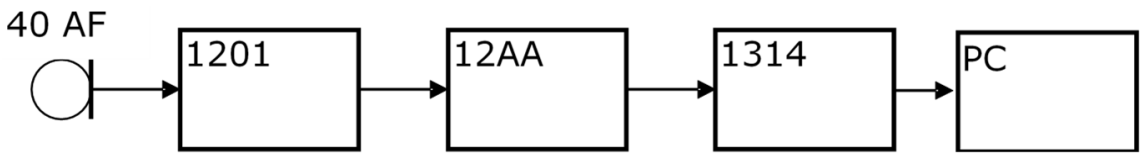

Fig. 3. The block diagram of the measuring setup, where: $40 \mathrm{AF}-$ G.R.A.S microphone, 1201 - NORSONIC preamplifier, 12AA - G.R.A.S amplifier, 1314 - M-AUDIO IN/OUT chart, PC - computer with Adobe Audition 3.0 software

\section{Results}

The acoustic signal parametrization was performed in the MDVP software package, offered by KAY ELEMETRICS [16].

Table 2. Comparison of signal parameters before and after manual therapy for patient no. 1. Vowel with prolonged phonation - "a"

\begin{tabular}{|c|c|c|c|c|}
\hline \multirow{2}{*}{ Parameter } & \multirow{2}{*}{ Shortcut } & \multicolumn{2}{|c|}{ Value } & \multirow{2}{*}{ Unit } \\
\cline { 3 - 4 } & & Before & After & \\
\hline Average fundamental frequency & Fo & 187.43 & 186.38 & $\mathrm{~Hz}$ \\
\hline Mean fundamental frequency & MFo & 187.35 & 186.34 & $\mathrm{~Hz}$ \\
\hline Average pitch period & To & 5.33 & 5.36 & $\mathrm{~ms}$ \\
\hline Highest fundamental frequency & Fhi & 204.25 & 194.99 & $\mathrm{~Hz}$ \\
\hline Lowest fundamental frequency & Flo & 163.71 & 175.91 & $\mathrm{~Hz}$ \\
\hline Standard deviation of Fo & STD & 3.94 & 2.68 & $\mathrm{~Hz}$ \\
\hline Phonatory Fo-Range in semi-tones & PFR & 5 & 2 & \\
\hline Fo-tremor frequency & Fftr & 5.33 & 5.55 & $\mathrm{~Hz}$ \\
\hline Amplitude tremor frequency & Fatr & 5.47 & 5.63 & $\mathrm{~Hz}$ \\
\hline Length of analyzed sample & Tsam & 9.33 & 5.88 & $\mathrm{~S}$ \\
\hline Absolute jitter & Jita & 44.19 & 24.36 & $\mu \mathrm{s}$ \\
\hline Jitter percent & Jitt & 0.83 & 0.45 & $\%$ \\
\hline Relative average perturbation & RAP & 0.51 & 0.24 & $\%$ \\
\hline Pitch perturbation quotient & PPQ & 0.36 & 0.22 & $\%$ \\
\hline Smoothed pitch perturbation quotient & sPPQ & 1.64 & 1.25 & $\%$ \\
\hline Fundamental frequency variation & vFo & 2.10 & 1.44 & $\%$ \\
\hline Shimmer in dB & ShdB & 0.23 & 0.14 & $\mathrm{~dB}$ \\
\hline Shimmer percent & Shim & 2.77 & 1.69 & $\%$ \\
\hline Amplitude perturbation quotient & APQ & 1.91 & 1.34 & $\%$ \\
\hline Smoothed ampl. Perturbation quotient & sAPQ & 4.84 & 4.82 & $\%$ \\
\hline Peak-to-Peak Amplitude Variation & vAm & 15.10 & 12.36 & $\%$ \\
\hline Noise to Harmonic Ratio & NHR & 0.14 & 0.13 & \\
\hline Voice turbulence index & VTI & 0.04 & 0.06 & \\
\hline Soft phonation index & SPI & 3.62 & 3.14 & \\
\hline Fo-tremor intensity index & FTRI & 1.26 & 0.98 & $\%$ \\
\hline Amplitude tremor intensity index & ATRI & 5.07 & 5.50 & $\%$ \\
\hline
\end{tabular}

In the pilot study for patient 1 and 2, 15 voice emission parameters improved. The analysis of the above results showed the variability before and after the diaphragm relaxation therapy in parameters such as Fo, Jitt and Shim [18]. Fo is the frequency of the fundamental vocal fold vibrations, while the Jitt parameter measures the cycle-to-cycle variation of this frequency, and the Shim parameter - the variability of the amplitude of the fundamental frequency of the vocal fold vibration during phonation. The Jitt and Shim values closer to zero indicate more effective work of the vocal folds through greater laryngeal stabilization. In the examined case of patient 1 and 2, the value of the parameter Jitt decreased by almost half, while Shim decreased by about $40 \%$ after the therapy. However, such changes were not observed for patient 3 . It may be 
influenced by many factors, such as stress or worse disposition on the day of the examination.

Table 3. Comparison of signal parameters before and after manual therapy for patient no. 2. Vowel with prolonged phonation - "a"

\begin{tabular}{|c|c|c|c|c|}
\hline \multirow{2}{*}{ Parameter } & \multirow{2}{*}{ Shortcut } & \multicolumn{2}{|c|}{ Value } & \multirow{2}{*}{ Unit } \\
\cline { 3 - 4 } & & Before & After & \\
\hline Average fundamental frequency & Fo & 179.13 & 177.99 & $\mathrm{~Hz}$ \\
\hline Mean fundamental frequency & MFo & 179.09 & 177.96 & $\mathrm{~Hz}$ \\
\hline Average pitch period & To & 5.58 & 5.619 & $\mathrm{~ms}$ \\
\hline Highest fundamental frequency & Fhi & 190.34 & 189.62 & $\mathrm{~Hz}$ \\
\hline Lowest fundamental frequency & Flo & 166.53 & 132.52 & $\mathrm{~Hz}$ \\
\hline Standard deviation of Fo & STD & 2.66 & 2.56 & $\mathrm{~Hz}$ \\
\hline Phonatory Fo-range in semi-tones & PFR & 3 & 7 & \\
\hline Fo-tremor frequency & Fftr & 4.87 & 4.93 & $\mathrm{~Hz}$ \\
\hline Amplitude tremor frequency & Fatr & 4.87 & 5.12 & $\mathrm{~Hz}$ \\
\hline Length of Analyzed Sample & Tsam & 11.18 & 13.31 & $\mathrm{~S}$ \\
\hline Absolute jitter & Jita & 47.40 & 35.34 & $\mu \mathrm{s}$ \\
\hline Jitter percent & Jitt & 0.84 & 0.62 & $\%$ \\
\hline Relative average perturbation & RAP & 0.49 & 0.39 & $\%$ \\
\hline Pitch perturbation quotient & PPQ & 0.46 & 0.30 & $\%$ \\
\hline Smoothed pitch perturbation quotient & sPPQ & 1.05 & 0.73 & $\%$ \\
\hline Fundamental frequency variation & vFo & 1.48 & 1.44 & $\%$ \\
\hline Shimmer in dB & ShdB & 0.25 & 0.16 & $\mathrm{~dB}$ \\
\hline Shimmer percent & Shim & 3.26 & 1.85 & $\%$ \\
\hline Amplitude perturbation quotient & APQ & 2.16 & 1.39 & $\%$ \\
\hline Smoothed ampl. Perturbation quotient & sAPQ & 5.23 & 4.36 & $\%$ \\
\hline Peak-to-peak amplitude variation & vAm & 22.51 & 23.82 & $\%$ \\
\hline Noise to harmonic ratio & NHR & 0.13 & 0.12 & \\
\hline Voice turbulence index & VTI & 0.03 & 0.02 & \\
\hline Soft phonation index & SPI & 15.73 & 11.41 & \\
\hline Fo-tremor intensity index & FTRI & 0.72 & 0.47 & $\%$ \\
\hline Amplitude tremor intensity index & ATRI & 5.37 & 3.96 & $\%$ \\
\hline & & & & \\
\hline
\end{tabular}

For patient 1 and 2, the same four parameters improved compared to their values before the therapy. The parameters STD and $\mathrm{vFo}$ are responsible for the values of the standard deviation of the fundamental frequency in the analyzed voice sample. Their improvement means that the frequency values in the entire signal are closer to the average fundamental frequency of the analyzed signal. The signal is less fluctuating than before therapy, which affects sound quality. The other two parameters (DUV and NUV), the values of which improved in patient 1 and 2, describe the degree of silence, i.e. the relative assessment of non-harmonic areas in the sample and the number of silent sections in the signal, which shows the better ability of the subject to continue talking (singing) after manual therapy. It is planned that the study will cover approximately 30 students of Academy of Music in Krakow, aged 19-26. The control group will consist of people aged 19-26 practicing singing at an amateur level.

\section{Conclusions}

The essence of taking care of voice hygiene is the knowledge of risk factors for the development of voice pathology in people who use voice on a daily basis during their professional duties. Research shows that the development of voice disorders is affected by, among others: age, sex, but also individual personal factors such as the duration and frequency of using voice throughout the day, number of performances, habitual chin extension, leaning during singing [15]. The present study refers to the impact of the diaphragm function on voice emission parameters. In the future it is planned the study on bigger group students of Academy of Music in Krakow with 
the control group.

Table 4. Comparison of signal parameters before and after manual therapy for patient no. 3 .

Vowel with prolonged phonation - "a"

\begin{tabular}{|c|c|c|c|c|}
\hline \multirow{2}{*}{ Parameter } & \multirow{2}{*}{ Shortcut } & \multicolumn{2}{|c|}{ Value } & \multirow{2}{*}{ Unit } \\
\cline { 3 - 4 } & & Before & After & \\
\hline Average fundamental frequency & Fo & 365.03 & 345.78 & $\mathrm{~Hz}$ \\
\hline Mean fundamental frequency & MFo & 364.99 & 345.72 & $\mathrm{~Hz}$ \\
\hline Average pitch period & To & 2.740 & 2.892 & $\mathrm{~ms}$ \\
\hline Highest fundamental frequency & Fhi & 398.96 & 389.62 & $\mathrm{~Hz}$ \\
\hline Lowest fundamental frequency & Flo & 335.51 & 329.18 & $\mathrm{~Hz}$ \\
\hline Standard deviation of Fo & STD & 3.73 & 4.28 & $\mathrm{~Hz}$ \\
\hline Phonatory Fo-range in semi-tones & PFR & 4 & 4 & \\
\hline Fo-tremor frequency & Fftr & 2.51 & 5.40 & $\mathrm{~Hz}$ \\
\hline Amplitude tremor frequency & Fatr & 4.87 & 5.33 & $\mathrm{~Hz}$ \\
\hline Length of Analyzed Sample & Tsam & 6.43 & 6.19 & $\mathrm{~S}$ \\
\hline Absolute jitter & Jita & 8.52 & 40.40 & $\mu \mathrm{s}$ \\
\hline Jitter percent & Jitt & 0.31 & 1.39 & $\%$ \\
\hline Relative average perturbation & RAP & 0.18 & 0.92 & $\%$ \\
\hline Pitch perturbation quotient & PPQ & 0.16 & 0.58 & $\%$ \\
\hline Smoothed pitch perturbation quotient & sPPQ & 0.53 & 0.87 & $\%$ \\
\hline Fundamental frequency variation & vFo & 1.02 & 1.23 & $\%$ \\
\hline Shimmer in dB & ShdB & 0.10 & 0.63 & $\mathrm{~dB}$ \\
\hline Shimmer percent & Shim & 1.10 & 7.35 & $\%$ \\
\hline Amplitude perturbation quotient & APQ & 0.82 & 4.06 & $\%$ \\
\hline Smoothed ampl. perturbation quotient & sAPQ & 4.27 & 8.13 & $\%$ \\
\hline Peak-to-peak amplitude variation & vAm & 14.00 & 15.12 & $\%$ \\
\hline Noise to harmonic ratio & NHR & 0.09 & 0.11 & \\
\hline Voice turbulence index & VTI & 0.03 & 0.02 & \\
\hline Soft phonation index & SPI & 13.35 & 14.90 & \\
\hline Fo-tremor intensity index & FTRI & 0.46 & 0.54 & $\%$ \\
\hline Amplitude tremor intensity index & ATRI & 6.19 & 8.05 & $\%$ \\
\hline
\end{tabular}

\section{Acknowledgements}

This research has been partly supported by AGH UST project No. 16.16.130.942.

Special thanks to the professor Zdzisław Madej, head of Voice Department at Academy of Music in Krakow.

\section{References}

[1] Kocjan J., Gzik Zroska B., et al. Impact of diaphragm function parameters on balance maintenance. PLoS One, Vol. 13, Issue 12, 2018, p. e0208697.

[2] Vostatek Novák P. D. Diaphragm postural function analysis using magnetic resonance imaging. PLoS One, Vol. 8 Issue 3, 2013, p. e56724.

[3] Wojtaszek A. Prevention and Voice Hygiene in Music Education in Children and Young People. Psychological-Pedagogical Notebooks of Artistic Education Centre, 2015, (in Polish).

[4] Marszalek S., Niebudek Bogusz E., Woźnicka E., Kowalska M. Ś. The application of physiotherapeutic and ostheopatic diagnostics in ocuppational voice disorders. Occupational Medicine, Vol. 61, Issue 2, 2010, p. 205-211, (in Polish).

[5] Sadowska, Dragun, Gutowska, Szczepaniak R. The meaning of the right body posture during speech therapy. Speech-Therapy Forum, Vol. 24, 2016, p. 59-70, (in Polish).

[6] Snell R. S. Clinical Anatomy by Regions. Philadelphia, Lippincott Williams and Wilkins, 2008.

[7] Kocjan J., Adamek M., Gzik Zroska B., Rydel M. Network of breathing. Multifunctional role of the diaphragm: a review. Advances in Respiratory Medicine, Vol. 85, 2017, p. 224-232. 
[8] Sielska Badurek E., Domeracka Kolodziej A. Evaluation of breath support in classical singing. Otorhinolaryngology, Vol. 8, Issue 3, 2009, (in Polish).

[9] Murray E. S. H., Michener C. M., Enflo L., Cler G. J., Stepp C. E. The impact of glottal configuration on speech breathing. Journal of Voice, Vol. 32, Issue 4, 2018, p. 420-427.

[10] Salomoni S., Van Den Hoorn W., Hodges P. Breathing and singing: objective characterization of breathing patterns in classical singers. PLoS ONE, Vol. 11, Issue 5, 2016, p. e0155084.

[11] Loor A., Nedelcut S., Dumitrascu D. L. High prevalence of gastroesophageal reflux in vocal opera students. A case-control type study. Medicine and Pharmacy Reports, Vol. 93, Issue 2, 2020, p. $145-149$.

[12] Śmieszchalska J. Prevention of ailments resulting from specificity of playing musical instruments new challenge for teachers. Psychological-Pedagogical Notebooks of Artistic Education Centre, 2015, p. 55-68, (in Polish).

[13] Bordoni B., Marelli F. The fascial system and exercise intolerance in patients with chronic heart failure: hypothesis of osteopathic treatment. Journal of Multidisciplinary Healthcare, Vol. 8, 2015, p. 489-494.

[14] Bordoni B., Marelli F., et al. Manual evaluation of the diaphragm muscle. International Journal of Chronic Obstructive Pulmonary Disease, Vol. 11, 2016, p. 1949-1956.

[15] Phyland D., Miles A. Occupational voice is a work in progress: active risk management, habilitation and rehabilitation. Current Opinion in Otolaryngology and Head and Neck Surgery, Vol. 27, Issue 6, 2019, p. 439-447.

[16] Wierzbicki J., Malecki P., Wiciak J. Localization of the sound source with the use of the first-order ambisonic microphone. Acta Physica Polonica. A, Vol. 123, Issue 6, 2013, p. 1114-1117.

[17] Kay Elemetrics: Multi-Dimensional Voice Program (MDVP) 5015 Software Instruction Manual. New Jork, 2005.

[18] Klaczyński M. Vibroacoustic methods in diagnosis of selected laryngeal diseases. Journal of Vibroengineering, Vol. 17, Issue 4, 2015, p. 2089-2098.

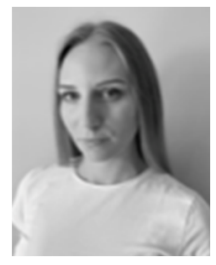

Julia Ciuryk in 2018 received a Bachelor's degree in physiotherapy in the Jagiellonian University - Collegium Medicum, Krakow, Poland. Currently is continuing studies at the Masters degree and works at the private physiotherapy clinic in Wroclaw. Participant of many conferences and courses, in 2019 got an internship in New York College of Podiatric Medicine. The interest in polyphonic music and the white singing technique resulted in the desire to investigate the influence of manual therapy on voice emission. Julia Ciuryk was responsible for conceptualization, data curation, investigation, methodology and writing this manuscript.

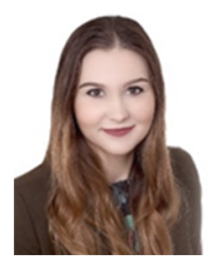

Dominika Michalik received her Master's degree in physiotherapy from the Jagiellonian University Medical College in Poland in 2020. Former president of Student Scientific Group of Physiotherapy and Neurorehabilitation at Jagiellonian University Medical College. Research areas include pelvic floor physiotherapy and visceral therapy. Dominika Michalik was responsible for conceptualization, data curation, investigation and methodology in this project.

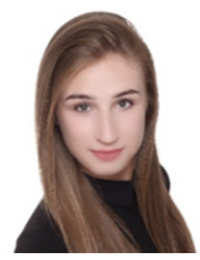

Katarzyna Hordyjewicz received a Bachelor's degree in physiotherapy at the Jagiellonian University - Collegium Medicum, Krakow, Poland, in 2018. Currently undergoing second-cycle studies. Research areas: manual and visceral therapy, musicians' physiotherapy, physiotherapy in orthopedics and neurology. Katarzyna Hordyjewicz was responsible for data curation and investigation in this project. 


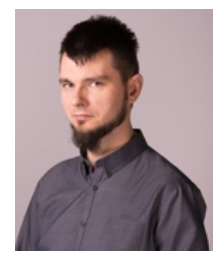

Pawel Malecki, Ph.D. D.Sc. Eng. His research activity is focused mostly on the psychoacoustic aspects of choral music perception in the diffused field and application and development of auralization techniques combined with ambisonics. He is an author of over 100 scientific publications on room acoustics, sound perception, sound source localization and soundscape analysis. He is an assistant professor at the AGH University and works as a freelance sound engineer and acoustic consultant. He is an AES and EAA regular member and a former officer of the Polish Acoustical Society. Paweł Małecki was responsible for conceptualization, data curation, formal analysis, investigation, methodology, software, validation and writing this manuscript.

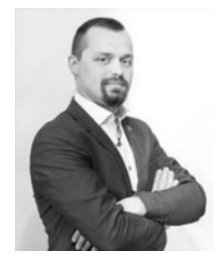

Grzegorz Frankowski M.Sc., assistant at the Physiotherapy Institute of the Faculty of Health Sciences, Medical College of the Jagiellonian University in Krakow, UJCM. The main directions of his research is posturography, sEMG and possibility of the electromyographic signal for the diagnosis ambulatory patients with limited motor functions. Member of Polish Lymphological Society (PTL). Grzegorz Frankowski was responisble for investigation and validation in this project.

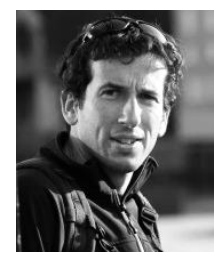

Maciej Kłaczyński Ph.D. D.Sc. Eng. Prof. AGH, works at Department of Mechanics and Vibroacoustics in AGH University of Science and Technology in Krakow. His research is focused on measurement, signal processing and pattern recognition methods of vibroacoustic signals applied in medicine, technology and environmental monitoring. Author of over one hundred scientific publications and conferences papers. Member of European Acoustics Association (EAA), Polish Acoustical Society (PTA) and Polish Society of Technical Diagnostics (PTDT). Maciej Kłaczyński was responsible for conceptualization, data curation, formal analysis, investigation, methodology, software, validation, writing manuscript and this project administration.

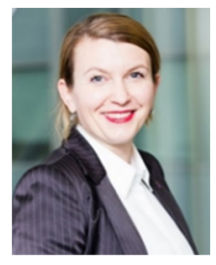

Malgorzata Kulesa-Mrowiecka, Ph.D., M.Sc., Assistant Professor at the Physiotherapy Institute of the Faculty of Health Sciences, Medical College of the Jagiellonian University in Krakow. Lecturer at numerous national and international conferences. Author of numerous publications and speeches on the physiotherapy of the masticatory organ functional system (MOFS). She curates the Students Scientific Club for Physiotherapy and Neurorehabilitation. Author of the book and chapters in the books connected with her research area: neurorehabilitation, craniomandibular dysfunctions, posturology, gnathology, osteopathy. Organizes the annual conferences entitled CRANIA "Consensus in the diagnosis and physiotherapy of the temporomandibular joints". She is a member of: Polish Society of Face and Cranium Treatment, The International Society of Physical and Rehabilitation Medicine. Małgorzata Kulesa-Mrowiecka was responsible for conceptualization, investigation, methodology, writing manuscript and this project administration. 